\title{
Digihoax: An Evolution of the Noise in the Indonesian Modern Communication Culture
}

\author{
Rr Dinar Soelistyowati \\ Department of Communication Arts \\ University of Bhayangkara Jakarta Raya \\ Bekasi, Indonesia \\ dinar.soelistyowati@dsn.ubharajaya.ac.id
}

\begin{abstract}
In this day and age, of course there is a lot of variety of information that we can get from various media. We can get almost all forms of information in accordance with what we need. One form of information we need is news, and the two communication media that have access like that are none other than the internet and social media. With the presence of these two media, a wealth of news information can be obtained quickly and accurately in just a few clicks. However, in spreading the news we receive, there are not a few parties who want to take a negative role to create a sensation of mere excitement. The sheer excitement we have long known as hoaxes. This study aims to provide an overview of how hoaxes can develop and influence audiences, especially for internet and social media users. This discussion covers how hoaxes are created, developed and influential among citizens and their anticipation in finding information that is clean from hoaxes so that they become intelligent citizens in navigating digital information networks. This study uses a qualitative method by combining the theory of semiotics in mass communication with the theory of group cohesiveness as a grand theory and the theory of transmission as a middle range theory in the psychology of communication. The results obtained from this study show how hoaxes are able to adapt and develop in line with the shift in the development of communication which was originally in the form of conventional (word of mouth) to modern communication (user to user) so that it evolved into digihoax.
\end{abstract}

Keywords: digihoax, internet, social media, modern communication culture

\section{INTRODUCTION}

Th In modern times like this, communication becomes a necessity for every human being. Whatever we will think or want, we need to communicate to explain these thoughts or desires to others. Not only that, to expedite communication activities also need to be updated so that they can follow the nature of dynamism and human flexibility in every verbal activity. The update is done by synchronizing communication into communication media, especially on new media such as the internet and social media.
In the digital era like now, the internet and social media are present as well as giant encyclopedias for the human digital social environment itself. Now the real world and the virtual world are almost no different anymore. How not, everything that is done in the real world can be done in cyberspace. We can do learning, playing, doing business, working, socializing, even recreation in cyberspace [1]. This makes the internet and social media an extension of mobility, visual senses, and human thought.

Unfortunately, the high growth of internet penetration and smart phones (smartphones) in Indonesia is not accompanied by a variety of understandings of media literacy. This happens because technology is currently facing a period of transition, especially in the older generation or what we call digital immigrants. As a group that is not yet well-versed with the development of the media, they need more time to understand the culture and functional of online products. Thematically, information flows continuously through social media, chat groups and news channels. This results in the inability of the community to explore this information fully and correctly, but has a strong desire to share it immediately with others let alone news that is unusual (anti-mainstream). As a result, some information received results in many interpretations and points of view which lead to misunderstanding. In Indonesia alone, cases like this are usually often found, generally in the political field. This is what triggers the formation of hoax [2].

The existence of hoax itself has long existed in Indonesia. Hoax appeared long before the internet appeared in the midst of society. However, perhaps most people do not yet know the real terms and practices of hoax. Lack of public understanding of hoax occurs because of the strict rules governing the circulation of media and news, so that hoax can be controlled and can be prevented. However, since the internet entered into the social layer of Indonesian society, hoax have become a phenomenon that should be watched out by Indonesian people. Significant information dissemination due to the explosion of information, led to the emergence of parties who played a negative role in spreading sensational news and information, creating a furor and panic in the virtual universe [3]. 
Seeing the above phenomenon, many preventive efforts made by the government to control the growth of hoax in Indonesia, ranging from blocking social media, selection of news content distribution, hoax socialization to the public, to restrictions on the use of the internet as happened some time ago when the virtual world situation heats up when the 2019 presidential election. At least, there are several sites that had previously been blocked by the Ministry of Communication and Information (Kemkominfo) related to cybercrime cases such as hoax. These efforts are carried out in the hope of being able to minimize the growth and circulation of hoax in Indonesian cyberspace and to re-establish valid and constructive information to support positive dynamism and information flexibility for Indonesia's digital society.

This research was conducted with the aim of knowing and understanding more deeply about the creation of hoax in cyberspace so that it evolved into digihoax, the process and pattern of the spread of digihoax through the internet and social media, latent impact of digihoax both on the smallest scope of scale, namely individuals, medium scale, i.e between fellow internet and social media users, and on a large scale, between groups that are active internet and social media users, and their anticipation of the development and circulation of digital media in order to create intelligent and careful digital communities in navigating the flow of information in cyberspace as well as the formation of a secure internet environment, comfortable, and responsible.

\section{METHOD}

This research is qualitative, with phenomenology as a research method and accidental sampling as a data collection technique. These methods and techniques were chosen because of the widespread distribution of digihoax into news information consumed by the public through internet access and social media, so an in-depth study of this phenomenon is needed. In the process, this research uses a combination of semiotic theory with group thought theory as the grand theory of research and transmission theory as a middle range research theory.

\section{THEORETICAL STUDY}

From some of the results of previous studies, it can be described the difference between previous research with this research that is using the same theory but different in objects and situations and the objectives of the research. This research is focused on providing an overview of the process of creating hoax in cyberspace until it evolves into digihoax. But from some of the results of previous studies that have been described there are previous studies that approach their similarities with the research object of researchers in broad outline. From the list of previous studies, Christiany Juditha's research entitled "Interaction of Hoax Communication in Social Media and its Anticipation" is the closest approach to the research of researchers. This similarity is due to the focus of his research on the description of the interaction of hoax communication on social media and its anticipations. The research was made with the aim of getting a picture of the interaction of hoax communication on social media and how to anticipate it. In his research, he uses qualitative research methods with case studies as a method of gathering research data. The findings of the research that has been done are that communication interactions are found to be built very dynamically. The sender or recipient of a hoax message is a party that does not like the government. Other recipients of the message are those who disagree and deny the hoax as support for the government.

This is what later became a reference for researchers in conducting research on Digihoax. Researchers make this research with the aim of giving an idea of how hoaxes can develop and influence audiences, especially for internet and social media users. In conducting its research, researchers also used qualitative research methods with accidental sampling as a technique for collecting data from this study. Through this research, researchers hope the findings from their research can show how hoaxes are able to adapt and develop in line with the shift in the development of communications that were originally conventional (word of mouth) to modern communication (user to user) so that they evolve become digihoax.

\section{A. Semiotics Tradition}

The semiotic tradition is rooted in language. This tradition tries to discuss the nature of symbols that contain certain meanings in the communication process. Symbols are a cultural product of a society to express ideas, meanings, and values that exist in themselves.

The semiotic tradition is formed of three studies, namely:

1. Semantics, studies that explain how the signs relate to what the signs show.

2. Syntatic, a study that links one sign with another sign, meaning that a sign cannot stand alone.

3. Pragmatics, examines how signs can make a difference in human life [4].

\section{B. Communication}

According to Pearson and Nelson, communication is the process of understanding and sharing messages [5]. The definition is explained like that because at the core of communication science is a relationship that involves interaction between participants. This definition also emphasizes the process that will understand and share the perspectives of others effectively through four keywords, namely (1) a process that is an activity that was initially difficult to explain because it is changing, (2) understanding to assume, interpret, and connect our perceptions and interpretation to what we already know, (3) sharing means to do something together both with one or many 
and has since been seen as an important variable in group effectiveness. Cohesiveness is a level of dual interest among group members. In a very coherent group, a double identification keeps a group together. Integration is a result of the degree to which all members feel that their goals can be achieved within the group. This does not require members who have the same attitude, but members who show a degree of interdependence, rely on one another to achieve the desired goals. The more integrated the group, the more pressure the members will press to maintain the cohesiveness

Cohesion can be a good thing as it brings its members together and strengthen interpersonal relationships. Although Janis did not dispute the potential value of effectiveness, she was also aware of the dangers. For someone, a very coherent group might spend too much energy in maintaining good intentions in a group that interferes with decision making. Members infuse too much intrinsic energy into the group because of prizes: friendship, prestige, and recognition of self-esteem. Because of our high self-esteem, we sometimes devote too much energy to building positive relationships, and this can lead to group thinking. Janis discovered in her research that group thinking can produce something negative:

1. Groups limit discussion to only a few alternatives without considering creative possibilities. The solution is clear and simple for the group, and there is little exploration of other ideas.

2. The initial position given by most members is never reviewed again to look for the unexpected. In other words, the group is not critical in testing the branching solutions.

3. The group fails to retest all alternatives that are not of the majority. Minority opinion was quickly dissolved and ignored, not only by the majority, but by all who were initially one-sided.

4. Expert opinion is not sought. Groups are satisfied with their own opinions and abilities to make decisions and may feel threatened by outsiders.

Irving L. Janis explained that group communication is a theory of thought to show a cohesive or integrated mode of group thinking of people, when hard efforts are made by group members to reach consensus. Associated with the same topic, Mulyana provides a definition of group communication as a situation in the decision making process that shows the growth of mental efficiency deterioration, reality testing and moral judgment caused by group pressures. Whereas Rachmat defines group communication as a decision-making process that occurs in highly cohesive groups, where members try to maintain group consensus so that their critical abilities are no longer effective [9].

Group thinking is a direct result of group cohesion which has been discussed in several sections by Kurt Lewin in the 1930s
5. Groups are very selective in gathering and presenting information. Members tend to focus only on information that supports the plan.

6. The group is so confident with its ideas that do not consider the possibilities of the plan. This is unpredictable or the possibility of a plan failed.

All of these things are the result of less critical thinking and from overly confident groups. Janis maintains all these predictable results with a number of symptoms that effectively summarize the contents of group thinking. These symptoms include: 
Individual members are reluctant to express opposing opinions and suppress them in silence.

7. There is an illusion of unanimity in the group. Even if a decision has been agreed upon, the group finds a position of solidarity.

Finally, group thinking involves the emergence of self-raised mindguards to protect the group and leaders from opposing opinions and unwanted information. Vigilance usually suppresses negative information by consulting members not to complicate it [10].

\section{G. Groupthink Model}

The process of creating a groupthink involves two main elements (Fig 1). The first element is decision makers, where if the group has high cohesiveness, it will bring up the second element in the form of antecedent factors (box A), which are things that precede intended to improve group thought, then the decision made by the group will be of poor value. However, if the preceding things are intended to prevent group thought, then the decision to be made by the group will be of good value.

OBSERVABLE CONSEQUENCES

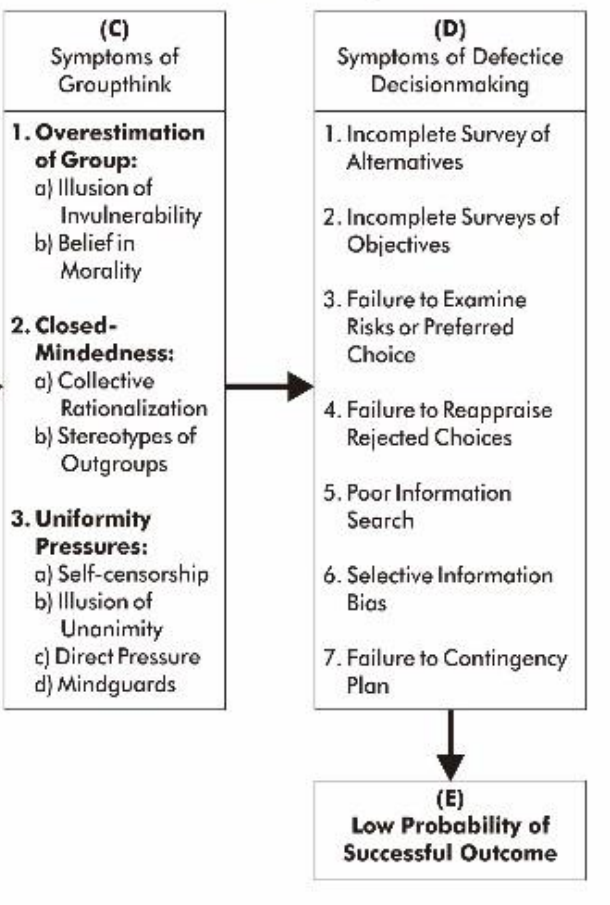

Fig. 1. Process of creating a groupthink [11] 


\section{H. Transmission Theory}

This theory states that in a publicity every feeling and action is contagious, follows only instincts, is irrational and is unable to control one's own behavior. In its implementation, every individual who is exposed to the impact of Digihoax has a tendency to be able to transmit irrational attitudes and behavior to others who are still neutral towards digital media content that contains hoaxes. This creates unsafe, unhealthy and irresponsible internet conditions that can be psychologically fatal.

\section{RESULTS AND DISCUSSION}

\section{A. The Description of Hoax at the Indonesian Millenial Social Environment}

According to a survey conducted by the Indonesian Telecommunications Society [12] in 2017, only 14.40 percent of Indonesian people were aware of the hoax content in the news. Whereas 31.90 percent of them only learned the truth when there was clarification from social media, following clarification from mass media such as television by 21.90 percent [12]. This proves that the role of the internet and social media in the spread of hoaxes in Indonesia is very large. In general, the environment of Indonesia's millennial society is always dependent on the internet and social media. This also makes them vulnerable to hoax circulation. Quoted from the results of a survey conducted by the Daily Social, when an information or news that contains hoaxes reaches the public, whether it is obtained from internet access or from social media, they tend to read the information as a whole. Actually, in plain view, that is a good thing. However, it would be bad if they just read without being accompanied by considerations or verification measures of the validity of the information. It also gets worse when after reading the information, most of them (77.76 percent) forward the news they receive to others, both between individuals and to a group only if it is considered important, even if the news is not important for those who get the news channel [2].

In modern life such as this time it also does not make the incarnated community a part of this millennial era as a human being alert to the news content they receive. This is because many of them often receive hoaxes, but because it does not make verification as part of a positive digital communication culture and tends not to do anything it makes it difficult for them to recognize and distinguish between original and fake news [2].

\section{B. Hoax Evolution Process Becomes Digihoax}

When the communication media develops to a higher stage such as new communication media, so does the noise in communication. When the hoaks begin to reach the level of digital communication, the noise goes through three stages of the semiotic process, namely:
1. Semantics, studies that explain how the signs relate to what the signs show.

2. Syntatic, a study that links one sign with another sign, meaning that a sign cannot stand alone.

3. Pragmatics, examines how signs can make a difference in human life [4].

If this semiotic theory is based on Lasswell's basic communication formulation, then a detailed explanation of the semiotics process towards hoaks is as follows:

Hoax that will be disseminated through digital communication media are processed semantically, i.e. what signs will be given to information to be turned into false information (hoax). Because the news or information on this hoax cannot be spread by itself, the false information then enters a synthetic phase, where this information requires (1) victims can be individuals or groups - to receive information and (2) motives given by the perpetrators to make individuals or groups accept false information. After the perpetrators of the information obtain the right targets and motives for sending the false information, the false information is ready to enter the final phase, the pragmatic phase. In this phase, the perpetrators of false information need the right media to spread hoax, in which case the chosen media is digital media, then determine the right time to spread the hoax, and determine the right way or method, namely through the internet and social media. After the five elements $\mathrm{W}$ (what, who, why, which, when) and $\mathrm{H}$ (how) have been fulfilled, the hoax automatically evolves into digihoax.

\section{Digihoax Deployment Process on the Cyberspace Network}

When digihoax is received by individuals or even groups, a group thought process begins with a process breakdown like the following:

When the community, whether its position as an individual or as a member of a social group, receives fake digital information, whether it is accessed via the internet or entered through its social media, then unconsciously it will make structural errors (structural faults) in the form of:

1. Insulation of Group - people do not try to find or allow outsiders to offer their own opinions. In this section, they are more likely to continue to follow the information content available on the internet and their social media than to ask about the accuracy of the information they receive.

2. Lack of Tradition of Impartial Leadership - In this section, the chairperson of a community group openly makes conclusions, whether at the beginning, during, or after this false information is spread on the internet or on social media groups the. 
thinking. Symptoms experienced by the community in this section include: section, community groups do not have special consideration in reviewing the content of false information they receive from the internet or social media.

4. Homogeneity of Group's Background / Ideology Communities have similarities in terms of background or ideology that makes it easy for actors to spread false information on the internet or their social media.

The impact of this error will be more fatal if there are provocative elements of context (Provocave Context) such as:

1. High Stress of External Threats - the community feels stress due to the impact of recent problems in the environment around the community group /

2. Low Self Esteem - As a result of the severity of the problems faced by the group becomes a moral dilemma for the group which then causes the low self-esteem owned by the group.

When people already have these antecedents, they will tend to seek agreement on a decision (concurrence-seeking of decision) that will result in group thinking, where the group's thinking will lead to the conditions that trigger the symptoms of group thought such as:

1. Overestimation of Group, including:

a. Illussion of Invulnerability - Here the community already feels and thinks that the decision making of their conclusions on false information is no longer in doubt, thus encouraging them to take extreme risks if there are things that conflict with the community's perception.

b. Believe In Inherent Group - For people who have been exposed to group thought will assume that the conclusion is the most correct than other community members.

2. Closed Mindedness. When community thoughts become closed, then they will tend to ignore what is said by other community members. These symptoms include:

a. Collective Rationalization - This will cause people to tend to ignore all kinds of other opinions that conflict with their own opinions.

b. Stereotypes of Out-Groups - For people who are exposed to group thought, they will tend to stereotype that people who have different opinions are not part of that society.

3. Pressure Toward Uniformity - Because the community has been exposed to group thought, there will be pressure that tends to force them to have uniform a. Self-Censorship - This creates a community that has a group mindset that suppresses any doubts they may have about any disagreement about the decisions they have made in the past.

b. Illusion of Unanimity - as a further effect of selfcensorship, the community will assume that all members of the community have the same voice.

c. Direct Pressures on Dissenters - If there are members of the public who have different voices, then other members will coax forcefully not to oppose their thoughts in the form of sanctions.

d. Mindguards - This will make community members tend to protect the original initiators of group decisions from outside information that threatens the final form of decisions that have been made before.

If the community has shown signs of group thought, at the same time they will show symptoms of making defective decisions (symptoms of defective decision-making), such as:

1. The results of the discussion are very limited to alternative decisions (Incomplete Survey of Alternatives);

2. Tendency to not survey policies incompletely and perfectly (Incomplete Survey of Objectives);

3. No evaluation or re-evaluation of previously selected problem solving (Failure to Examine Risk of Preferred Choice);

4. The tendency to not reconsider the decision they rejected (Faliure to Reappraise Rejected Choice);

5. The tendency to not seek expert opinion on the decisions they have made (Poor Information Search);

6. If there is any other advice or consideration, acceptance of this matter will be very selective because of the tendency of bias from the community members (Selective Information Bias), and;

7. Tend not to see any opposition from other groups so they do not prepare for anticipation (Failure to Contingency Plan) [13].

If a community group has been affected by digihoax having such impacts, then it is less likely to make good decisions (low probability of successful outcome). 
world that is responsible for the fulfillment and consumption of information. The suggestions writer can give are as follows:

1. Before receiving information, it should be sure that the news or information is true without any elements that are exaggerating, are helpful in the implementation of our daily lives, have legal legality, and are needed in life we, so that the information has a positive value when we spread the information to others.

2. Be always a person who upholds the principle of confidentiality of information, especially related to himself when interacting with people we meet in cyberspace by not spreading the contents of our account both in terms of security and social morals. This is done to prevent new crimes in the cyber world that indirectly carry and make us a scapegoat in these crimes.

3. Do not make networking sites and social media as a new center for social communication if you do not have the necessary social skills and requirements. If it is not accompanied by the ability and social requirements needed to interact in cyberspace, it will cause moral disturbance which will then trigger jealousy and social inequality in digital aspects.

\section{REFERENCES}

2. Always maintain privacy by not spreading personal information "for free" on social media.

3. Maintain account security, one of which is by creating passwords that are difficult to guess, as well as making changes to keywords regularly.

4. Always clarify when receiving information, whether it's access from the internet or who enter our social media.

5. Always spread positive information to minimize news hijacking by irresponsible parties.

6. Use social media only if deemed necessary, such as to help develop personal quality [14].

\section{CONCLUSION}

Based on the results of research and discussion, it can be concluded that the hoax that develops through a network of social networking sites and media can have a greater impact when compared to conventional hoax distribution. This is because the weak side of information transparency results in the loss of social barriers between users of the new media so that it can trigger social emotions en masse. The results obtained from these cyber turmoil can create unhealthy, safe and responsible internet conditions.

Based on the discussion and conclusions that have been outlined by the author, suggestions and input can be given in making the community as part of the social element of the digital
[1] Donny, B., \& Magdalena, M. (2018, February 22). Internet Sehat Pedoman Berinternet Aman, Nyaman, dan Bertanggung Jawab. Retrieved from Literasi Digital.

[2] DailySocial.id. (2018, December 28). Hoax Distribution Through Digital Platform in Indonesia 2018. Jakarta: Jakpat. Retrieved from DailySocial.id.

[3] Universitas Indonesia. (2017). Stop Hoax! UILib Berkala, 3.

[4] Pawito. (2007). Penelitian Komunikasi Kualitatif. Yogyakarta: LKiS Pelangi Aksara.

[5] Pearson, J., \& Nelson, P. (2000). An Introduction to Human Communication: Undetstanding and Sharing. Boston: McGraw-Hill.

[6] Schmitz, A. (2012). An Introduction of Group Communication. Lard Bucket.

[7] Gastil, J. (2010). The Group in Society. London: Sage Publication.

[8] Siberkreasi. (2018). Mengenal Hoaks. Jakarta: Kemkominfo.

[9] Santoso, E., \& Setiansah, M. (2010). Teori Komunikasi. Yogyakarta: Graha Ilmu.

[10] Littlejohn, S. W., \& Foss, K. A. (2014). Teori Komunikasi (9th ed.). (M. Y. Hamdan, Trans.) Jakarta: Salemba Humanika

[11] Irving L. Janis. Victims of Groupthink: A Psychological Study of Foreign-policy Decisions and Fiascoes. Houghton-Mifflin. 1972

[12] Mastel. (2017). Hasil Survey Mastel tentang Wabah Hoax Nasional. Jakarta: MASTEL.

[13] Yasir. (2012, March 14). Teori Pemikiran Kelompok - Groupthink Theory. Retrieved June 20, 2019, from staff.unri.ac.id yasir.staf.unri.ac.id/2012/03/14/teori-pemikiran-kelompok-groupthinktheory

[14] Kominfo. (2017). Bijak Bersosmed - Tips dan Informasi Gerakan \#BijakBersosmed 2017. Jakarta: Kominfo. 